\title{
Embodying the Meaning: The Role of Image Schemas, Metaphors, and Metonymies
}

\author{
There is no severing, separation from, or bleaching out of the bodily dimensions of meaning. Mind is embodied, meaning is \\ embodied, and thought is embodied in this most profound sense.
}

-George Lakoff and Mark Johnson ${ }^{1}$

The goal of this chapter is three-fold. First, to show how conceptual structure derives from embodiment by providing the reader with a general introduction to three theoretical notions that are central to the cognitive linguistic approach to embodied cognition, namely image schema, metaphor and metonymy. ${ }^{2}$ Second, to show how these guiding principles of embodied cognition play a crucial role in the grounding of the conceptual structure of mental causation that, as we have seen in the previous chapter, underlies the narrative organization of Kubrick's work. Third and last, to introduce the next chapter by outlining some of the theoretical challenges that arise when one attempts to connect the embodied conceptual structure to the formal structure of film.

\section{Embodiment and conceptual structure}

\subsection{Image schemas}

The notion of an image schema was jointly introduced by Mark Johnson and George Lakoff in their now classic 1987 monographs The Body in the Mind and Women, Fire, and Dangerous Things. With this notion both authors attempted to explain how the nature of human conceptual organization arises from the nature of human bodily interaction with the external world (i.e., the embodied cognition thesis). An image schema, as the name suggests, is a composite of two terms that, at first glimpse, seem to contradict each other. The term image suggests concreteness and refers to the type of experience upon which image schemas are founded, namely imagistic or sensory experience. Although the ordinary usage of the term image might favour the sensory domain of vision, it has a 
much broader application context in psychology and in cognitive linguistics, where it is used to denote all types of sensory-perceptual experience, some of which Evans and Green summarize as in table 2.1. ${ }^{3}$

Table 2.1 Some sensory-perceptual systems (after Evans and Green).

\begin{tabular}{lll}
\hline System & Sensory experience & Physical location \\
\hline Visual system & Vision & Eye, optic nerve \\
Haptic system & Touch & Beneath the skin \\
Auditory system & Hearing & Ear/auditory canal \\
Vestibular system & Movement/balance & Ear/auditory canal \\
\hline
\end{tabular}

The term schema suggests abstractness and refers to the nature of the concepts that derive from these imagistic experiences. Despite the fact that image schemas arise from perceptual interactions with the world, image schemas are not concrete concepts, but rather "abstract concepts consisting of patterns emerging from repeated instances of embodied experience." 4

Perhaps the easiest way to make sense of this conception of an image schema is with an illustration. Consider, for example, the following extract, as provided by Johnson, which describes only a small fraction of the many daily experiences of physical containment:

You wake out of a deep sleep and peer out from beneath the covers into your room. You gradually emerge out of your stupor, pull yourself out from under the covers, climb into your robe, stretch out your limbs, and walk in a daze out of the bedroom and into the bathroom. You look in the mirror and see your face staring out at you. You reach into the medicine cabinet, take out the toothpaste, squeeze out some toothpaste, put the toothbrush into your mouth, brush your teeth in a hurry, and rinse out your mouth. At breakfast you perform a host of further in-out moves-pouring out the coffee, setting out the dishes, putting the toast in the toaster, spreading out the jam on the toast, and on and on. ${ }^{5}$

What the recurrent use of the expressions in and out in this example shows, is not just a play with words. Rather, it suggests that a significant amount of daily activities can be organized around the same repeatable structure of experience (i.e., a schema). This recurrent pattern consists of a boundary distinguishing an interior from an exterior and constitutes what Lakoff and Johnson refer to as the image schema of CONTAINER. ${ }^{6}$ It is a gestalt structure in the sense that the parts only make sense with a whole. The meaning of one part depends on the relation to the other parts. There is only an outside if there is also a boundary and an inside, an inside if there is also an outside and a boundary, and a boundary if there are also sides.

Having an example of an image schema in mind, let us now explore its properties more in detail by looking into three fundamental assertions that are commonly put forward in relation to image schemas and that can be listed as follows:

- Image schemas are pre-conceptual and inherently meaningful.

- Image schemas have a logic.

- Image schema are inherently dynamic and come in clusters. 
The discussion that follows, draws significantly from a cross-reading of several authoritative sources in image schema research. In addition to the classic works of Lakoff and Johnson, these sources include, among others, Hampe's excellent edited volume on the importance of image schemas in cognitive linguistics and Evan and Green's outstanding summary of the properties of image schemas in their general introduction to cognitive linguistics. ${ }^{7}$

\section{Image schemas are pre-conceptual and directly meaningful}

The first assertion stems from the fact that image schemas, such as the conTAINer schema discussed above, are directly grounded in sensory experience. ${ }^{8}$ As the first concepts to emerge in the early stages of human development, they occupy a rather distinct status among other concepts. Because they are the foundations of the human conceptual system, they do not require understanding through other concepts. For instance, we come to understand a concept such as containment simply in virtue of human embodiment. Of course, we still have to learn that, in English language, words such as in and out designate this concept, but the concept itself needs, as it were, no further explication or reflection. The same can be said, for example, of such concepts as front and back which only make sense for beings with fronts and backs. As Lakoff and Johnson observe, "if all beings on this planet were uniform stationary spheres floating in some medium and perceiving equally in all directions, they would have no concepts of front or back." Because image schemas are pre-conceptual, they typically operate beneath the level of our conscious awareness. They are part of the category that Lakoff and Johnson refer to as the cognitive unconscious. ${ }^{10}$

As such, image schemas present us with two challenges. The first challenge is to identify them. Indeed, if image schemas exist as patterns beneath conscious awareness, how then can we bring them to the conscious level? As our example of the CONTAINER schema already indicated, one way to identify them is by way of what Johnson calls "a phenomenological description." ${ }^{11}$ The term phenomenological is here used not in the sense of Husserl's method of "transcendental reduction," but rather in the sense of a reflective interrogation of your own embodied experiences. As Johnson writes, "ask yourself what the most fundamental structures of your perception, object manipulation, and bodily movement are" and "certain obvious patterns immediately jump out at you." ${ }^{12}$ It is precisely by applying such a method that cognitive linguists over the years have identified a number of image schemas. Two provisional lists of them can be found in the works of Hampe and Evans and Green. ${ }^{13}$ Table 2.2 shows the list of Evans and Green as they were compiled by the authors from various sources, including, among others, Lakoff and Johnson. The image schemas are grouped according to the nature of the experiences that ground them.

Table 2.2 A partial list of image schemas (after Evans and Green).

\begin{tabular}{ll}
\hline SPACE & UP-DOWN, FRONT-BACK, LEFT-RIGHT, NEAR-FAR, CENTRE-PERIPHERY, CONTACT, \\
& STRAIGHT, VERTICALITY \\
CONTAINMENT & CONTAINER, IN-OUT, SURFACE, FULL-EMPTY, CONTENT \\
LOCOMOTION & MOMENTUM, SOURCE-PATH-GOAL \\
BALANCE & AXIS BALANCE, TWIN-PAN BALANCE, POINT BALANCE, EQUILIBRIUM \\
\hline
\end{tabular}




\begin{tabular}{ll}
\hline FORCE & COMPULSION, BLOCKAGE, COUNTERFORCE, DIVERSION, REMOVAL OF RESTRAINT, \\
& ENABLEMENT, ATTRACTION, RESISTANCE \\
UNITY/MULTIPLICITY & MERGING, COLLECTION, SPLITTING, ITERATION, PART-WHOLE, COUNT-MASS, LINK(AGE) \\
IDENTITY & MATCHING, SUPERIMPOSITION \\
EXISTENCE & REMOVAL, BOUNDED SPACE, CYCLE, OBJECT, PROCESS \\
\hline
\end{tabular}

The second challenge is to represent them. Because image schemas derive from experience, they are represented as analogue representations. ${ }^{14}$ The term analogue refers to a type of relationship in which the representations of the mind are analogically related to the sensory experiences or perceptual states that produced them. The American psychologist Lawrence Barsalou also calls these analogue representations perceptual symbols. ${ }^{15}$ They are contrasted with amodal symbols which, like words, are characterized by a type of relationship that is only arbitrarily related to the perceptual states that gave rise to them. Consequently, if image schemas are not represented in symbolic forms such as words, how, then, can we represent them? As the reader may have already noticed, most semantics, including cognitive linguists, use precisely symbolic forms such as words from natural language to represent pre-linguistic elements of meaning. For instance, in the field of cognitive semantics it is common to represent image schemas by using words in small capitals (e.g., CONTAINER). Another strategy that cognitive linguists often use to represent image schemas is by means of pictorial representations such as diagrams. ${ }^{16} \mathrm{~A}$ diagram has the advantage of representing concepts independently of language. For example, the three-part structure of the basic CONTAINER schema might be diagrammed by any bounded geometrical figure. Here, and henceforth, we will use the figure of a rectangle as the diagrammatical means to represent the CONTAINER schema: ${ }^{17}$

OUTSIDE

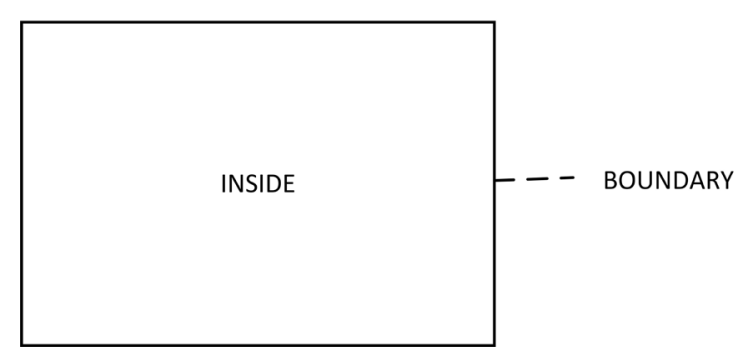

Figure 2.1 The CONTAINER image schema.

It is important to stress, however, that these drawings are not the image schemas themselves. We use these diagrams simply as a meta-language to characterize "some of the properties of the schemas" and "to get some idea of what they are like." 18 


\section{Image schemas have a logic}

Together with the image-schematic structure comes also its own logic. ${ }^{19}$ Consider, for example, what follows if you put some object $\mathrm{X}$ in your wallet (container $\mathrm{A}$ ) and you then place your wallet in your pocket (container B). By virtue of the internal spatial logic of containment, as diagrammed in figure 2.2 ( $\mathrm{X}$ is in $\mathrm{A}$ and $\mathrm{A}$ is in $\mathrm{B}$ ), it follows self-evidently that the object in your wallet is also in your pocket (X is in B). ${ }^{20}$

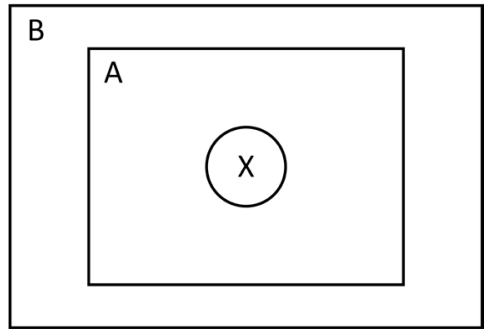

Figure 2.2 The CONTAINER image schema logic (after Lakoff and Johnson).

As Johnson points out, such apparently trivial spatial logic is by no means trivial. On the contrary, it is precisely this kind of spatial and bodily logic that allows us "to make sense of, and to act intelligently within, our ordinary experience." ${ }^{21}$

As a second example, consider the spatial logic of the SOURCE-PATH-GOAL image schema. ${ }^{22}$ Like the CONTAINER schema, this schema is one of the most fundamental schemas in our conceptual system. It underlies our basic experience of motion and is characterized by a trajector (henceforth, TR) that moves from one source location (the starting point) to another goal location (the ending point). ${ }^{23}$ Diagrammatically, its structure can be represented as in figure $2.3 .^{24}$

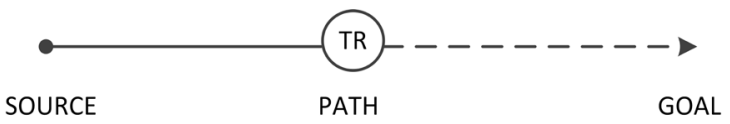

Figure 2.3 SOURCE-PATH-GOAL image schema (after Lakoff and Johnson).

As with the CONTAINER schema, one can draw an internal "logic" from the spatial relations inherent in this structure. According to Lakoff and Johnson this runs something as follows:

- If you have traversed a route to a current location, you have been at all previous locations on that route.

- If you travel from $\mathrm{A}$ to $\mathrm{B}$ and from $\mathrm{B}$ to $\mathrm{C}$, then you have travelled from $\mathrm{A}$ to $\mathrm{C}$.

- If there is a direct route from A to B and you are moving along that route toward B, then you will keep getting closer to B. 
- If $\mathrm{X}$ and $\mathrm{Y}$ are travelling along a direct route from $\mathrm{A}$ to $\mathrm{B}$ and $\mathrm{X}$ passes $\mathrm{Y}$, then $\mathrm{X}$ is further from $\mathrm{A}$ and closer to $\mathrm{B}$ than $\mathrm{Y}$ is.

- If $X$ and $Y$ start from $A$ at the same time moving along the same route toward $B$ and if $X$ moves faster than $\mathrm{Y}$, then $\mathrm{X}$ will arrive at $\mathrm{B}$ before $\mathrm{Y}^{25}$

Image schemas are inherently dynamic and come in clusters

A last important aspect that should be emphasized, is that image schemas are dynamic and highly flexible rather than fixed and static. Image schemas do not operate on their own, but they influence each other in various ways through processes of combination and superimposition, thus resulting in more complex and dynamic forms of image-schematic structures. A good illustration of this can be found in the interaction of the SOURCE-PATH-GOAL image schema with the image schema of FORCE. As we saw above, the first schema underlies our understanding of entities in motion. Entities, however, do not move on their own accord. As Johnson argues, entities move because "something with power" causes them to move. ${ }^{26} \mathrm{~A}$ ball moves into the goal because my foot made it move from outside the goal to the inside of it. This is where the notion of force comes into being. A force is that what imparts a directionality or vector quality on the moving entity. ${ }^{27}$ According to Johnson, FORCE schemas are typically held to consist of six properties. ${ }^{28}$ First, they are commonly experienced through interaction. For example, by bumping into the edge of a table, you experience the interactional character of force. Second, they have a vector quality in the sense that they usually involve the movement of some object (mass) through space in some direction (e.g., when I move my hand to grasp something, there is force exerted in a direction). Third, as a result of this vector quality, they typically involve a single path of motion. Fourth, they have sources or origins and because they are directional, they have targets. As Radden further explicates, these origins may be either internal as when people are guided by their intentions when moving their bodies, or external as when motion is brought about by physical laws (e.g., wind, water, physical objects, other people).$^{29} \mathrm{Fifth}$, they have a degree of power or intensity. One force can be stronger or weaker than another force. And sixth and last, they always involve a structure or sequence of causality, a consequence of having all the preceding properties (e.g. the door closes because I acted on it to cause it to shut).

Given these properties, then, one may distinguish between several schemas of motion and their associated force vectors. Johnson identifies no less than seven force schemas, two of which are illustrated in figure 2.4. ${ }^{30}$

A

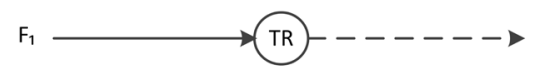

B

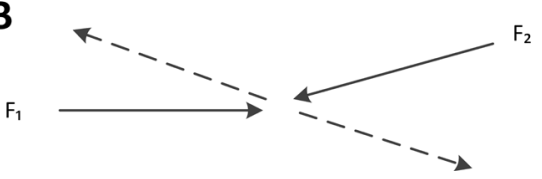

Figure 2.4 A, COMPULSION and $B$, DIVERSION schema.

The COMPULSION schema emerges from our experience of being brought in motion by an external force (e.g., being blown away by the wind, being pushed by other people). The DIVERsION schema occurs when our previous course of motion is being diverted by our encounter with another entity (e.g., swimming against a strong current). 
When the FORCE schema involves an interaction between two entities, such as is the case with the schemas above, we might also speak of a force dynamic pattern. This notion was introduced by the cognitive linguist Leonard Talmy to account for the various ways force interactions between entities might be conceptualized..$^{31}$ Force dynamic expressions such as "The ball kept rolling because of the wind blowing on it" typically involve a role difference between two force entities: one entity that is in focus and another entity that is opposing it. Talmy calls these entities the agonist (abbreviated Ago) and the antagonist (abbreviated Ant), respectively. ${ }^{32}$ In the expression the ball is the agonist and the wind is the antagonist. Force entities also have an intrinsic force tendency, either toward action or toward rest. In the example, the ball has a tendency toward rest. Another basic feature is the balance of strength between the two forces. The forces are out of balance by definition; if the two forces are equally strong, the situation is not interesting from a force-dynamic point of view. One force is therefore stronger or weaker than the other. In the example, the wind has a great power, since it overcomes the resistance of the force tendency of the ball (i.e., toward rest). Depending on the balance between the forces and the intrinsic force tendencies of the entities, there is also a resultant, either toward action or inaction (or rest). In the example, the ball moves and thus is not able to manifest its tendency toward rest.

FORCE and SOURCE-PATH-GOAL schemas, in turn, might be combined with other schemas such as the CONTAINER schema. This gives rise to what Robert Dewell labels "dynamic patterns of containment." ${ }^{33}$ Depending on the moving entity or trajector we focus upon (object and container, respectively), we might distinguish between several such patterns. Figure 2.5 shows two of them as they were discussed by Dewell. ENTRY refers to the experiential pattern according to which a smaller entity capable of motion moves from the outside toward the interior of a container, thus becoming the contained object (e.g., people walking into houses and rooms, people inserting things into jars or glasses). Figure $2.5 \mathrm{~A}$ represents the final stage of this path type whereby the dashed arrow corresponds to the prior locations of the trajectory.

A

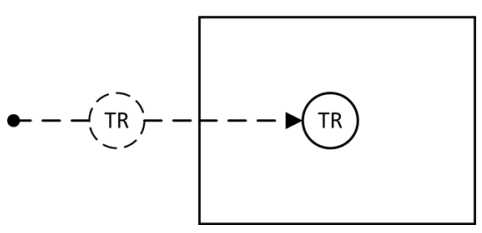

B

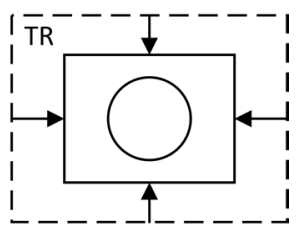

Figure $2.5 A$, ENTRY and $B$, ENCLOSING.

In ENCLOSING, by contrast, the container is the moving figure that closes in on the stationary object so as to exclude the free space that resides between the boundary of the container and the object inside of it (e.g., grasping hand, a wrapping napkin). Figure $2.5 \mathrm{~B}$ represents the final stage of this path type whereby the arrows represent the forces that are imposed on to the contained object by the container, thus eventually enclosing the object completely.

As we shall see in the next chapter, patterns such as these will be revealed to play a fundamental role in structuring the visible reality in front of the camera. 


\subsection{Metaphor and metonymy}

Having an idea of what image schemas are, let us now turn to a discussion of two assertions that further built on this notion and that, as we will see in the next part of this chapter, are of crucial importance in explaining how the conceptual structure of mental causation underlying Kubrick's work can be fleshed out by spatial knowledge. These assertions have to do with two other cognitive processes and might be put as follows:

- Image schemas provide the concrete basis for conceptual metaphors.

- Image schematic metaphors interact with metonymies.

As above, let us consider each statement in turn.

Image schemas provide the concrete basis for conceptual metaphors

Probably most important in the light of this book is the assertion that image schemas provide the bodily basis for the metaphorical nature of abstract concepts. ${ }^{34}$ This idea is central to what is now more broadly known as Conceptual Metaphor Theory (CMT). First proposed by Lakoff and Johnson in their now classic publication Metaphors We Live By, this theory makes the basic claim that metaphor is not simply a rhetorical tool of language, but a pervasive and essential feature of human thought. ${ }^{35}$ That is, conceptual structure is partly organized in terms of cross-domain mappings or correspondences between conceptual domains. A domain can be conceived of as a "body of knowledge that organizes related concepts." ${ }^{36}$ The conceptual domain that is being described in metaphorical terms is called a target domain and is usually abstract in nature. It involves concepts such as those identified in the preceding chapter (that is, concepts such as emotion, perception and causation which are all hard to understand without the assistance of metaphor). The conceptual domain that is used in order to describe the abstract target domain is called a source domain and is usually concrete in nature. ${ }^{37}$ The significance of image schemas, then, is that they can provide the concrete basis for these source domains. ${ }^{38}$ Their imagistic structure and inferential logic make them highly suitable for "fleshing out" the non-imagistic (i.e., abstract) realms of human experience. As such, conceptual metaphors have an experiential basis: they are grounded in the nature of our everyday experiences, or as Lakoff and Johnson so eloquently put it, they are "metaphors we live by." As a way of illustrating the mechanism of conceptual metaphor, let us consider the following statement about the effect that Kubrick's films have on the viewer, as it was expressed by Garreth Brown, inventor of the Steadicam and Kubrick's camera operator for The Shining (own emphasis):

Stanley Kubrick brought you into spaces in a really interesting way. His storytelling shots walked you in, and moved you into places that were memorably beautiful, beautifully lit, or strikingly presented in some way. But there are no ordinary spaces in his films. ${ }^{39}$

What is striking about this quotation, is that it represents an everyday way of talking about being "absorbed" in a film narrative. ${ }^{40}$ There is nothing stylized or overtly poetic about it. However, it is clearly non-literal. Kubrick 
cannot literally "bring" the spectator "into" the spaces of his films. Yet, Brown uses his own bodily knowledge (about forced movement into a container) in order to conceptualize his experience of seeing a Kubrick film (the target domain).

It is important to stress that the motivation for this metaphor resides at the conceptual level and not at the linguistic level. The linguistic metaphorical expressions are merely the manifestations of an underlying conceptual association between the concrete source domain and the abstract target domain. Therefore, as with image schemas, we are obliged to rely on language in order to communicate about conceptual metaphors. In the literature it is common to formalize the latter by making use of the shorthand notion "a is b" often in combination with the use of small capitals (e.g., CHANGE OF STATE IS MOVEMENT). This is simply a formal way to designate a series of discrete conceptual mappings which licence a range of linguistic examples.

Given that CMT provides us with a suitable theoretical tool for addressing abstract target domains and given that the conceptual structure underlying Kubrick's work (i.e., mental causation) can be characterized as highly abstract, it is plausible to assume that people also use the mechanism of conceptual metaphor to "flesh out" the latter. Addressing this hypothesis will be the central goal of the next section of this chapter. Before moving into this discussion, however, let us first consider the importance of another cognitive operation that has been emphasized by some scholars at least as important as conceptual metaphor in terms of providing structure to the human conceptual system (including abstract thought). In cognitive linguistic literature this mechanism is known by the name of conceptual metonymy.

\section{Image-schematic metaphors interact with metonymies}

Like metaphor, metonymy is claimed to be not just a purely linguistic device, but essentially a conceptual phenomenon that is central to human thought. ${ }^{41}$ Yet, despite this similarity, metonymy is also argued to be fundamentally different than metaphor. For instance, several authors have pointed out that metonymy, unlike metaphor, is not defined in terms of cross-domain mappings. ${ }^{42}$ Instead, it is defined by mappings within a single domain in which "one conceptual entity, the vehicle, provides mental access to another conceptual entity, the target." 43 Visually, this distinction might be represented as in figure 2.6.
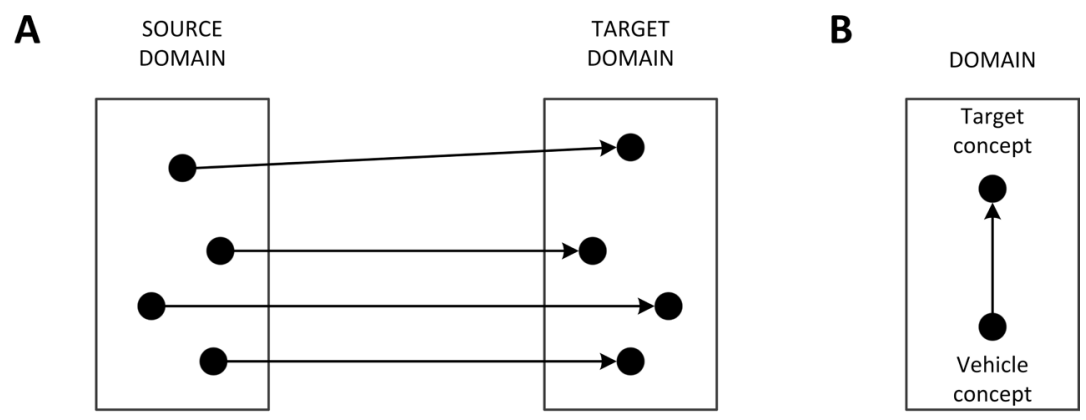

Figure 2.6 $A$, metaphor versus $B$, metonymy. 
To illustrate the mechanism of metonymy, consider, for example, the following expression as taken from the screenplay of Eyes Wide Shut (the vehicle is italicized):

Unexpectedly, his heart is filled with a feeling of tenderness and even of security. ${ }^{44}$

The reason why the vehicle in the expression above represents an instance of a metonymy is because both the target (tenderness and security) and the vehicle (heart) belong to the same conceptual domain (emotions). ${ }^{45}$ The heart is conceived of as a container that stands for its content (the feelings of tenderness and security). As this example indicates, metonymy is based on continuity or conceptual proximity rather than on conceptual distance, as it is the case with metaphor. Other examples of metonymies that have been cited in cognitive semantic literature, include, among others, PLACE FOR EVENT ("Iraq nearly cost Tony Blair the premiership") PLACE FOR INSTITUTION ("Downing Street refused comment") and PART FOR WHOLE ("My wheels are parked out the back"). ${ }^{46}$

In theory there seems to be little confusion about the distinction between metaphor and metonymy. In practice, however, both mechanisms are often blended together in close association. As Barcelona states, "they seem to be points on a continuum of mapping processes." ${ }^{\prime 7}$ Given that metaphor and metonymy are both conceptual, and given that they may in principle both relate to the same conceptual domains, questions arise concerning the interaction of metaphor and metonymy within the conceptual system. ${ }^{48}$ Consider, for example, the following expression as offered by Velasco:

She made every effort to attract him, and finally she has won his heart. ${ }^{49}$

Likewise, this example incorporates a metonymical mapping (HEART FOR LOVE), but this relationship is now also embedded in a metaphorical one in which obtaining someone's love is understood in terms of winning a prize (LOVE IS A PRIZE). In this metaphor, attaining someone's love is understood in terms of obtaining a reward whereby the lover must overcome some barriers in order to gain the prize of love. ${ }^{50}$ As such, both the vehicle and the target concept of the metonymical relationship are part of the same target domain of the metaphorical relationship. Schematically, this interaction might be diagrammed more generally as in figure 2.7 .

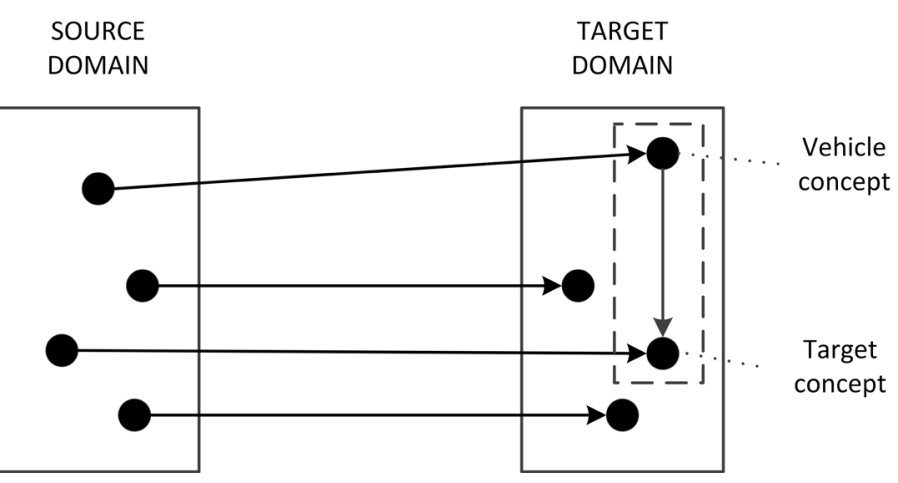

Figure 2.7 Metaphor-metonymy interaction. 


\section{Fleshing-out the conceptual structure of mental causation}

The discussion presented so far involved a general and brief introduction to the theoretical concepts that are central to the view of embodied cognition as developed within the field of cognitive linguistics. The central aim of this part is to illustrate them more concretely by applying them to the kind of abstract concepts that, in the previous chapter, were argued to constitute the literal, conceptual skeleton of Kubrick's narratives and that fall under the general category of mental causation. Figure 2.8 recalls these concepts as they together constitute the Western folk theory of emotion.

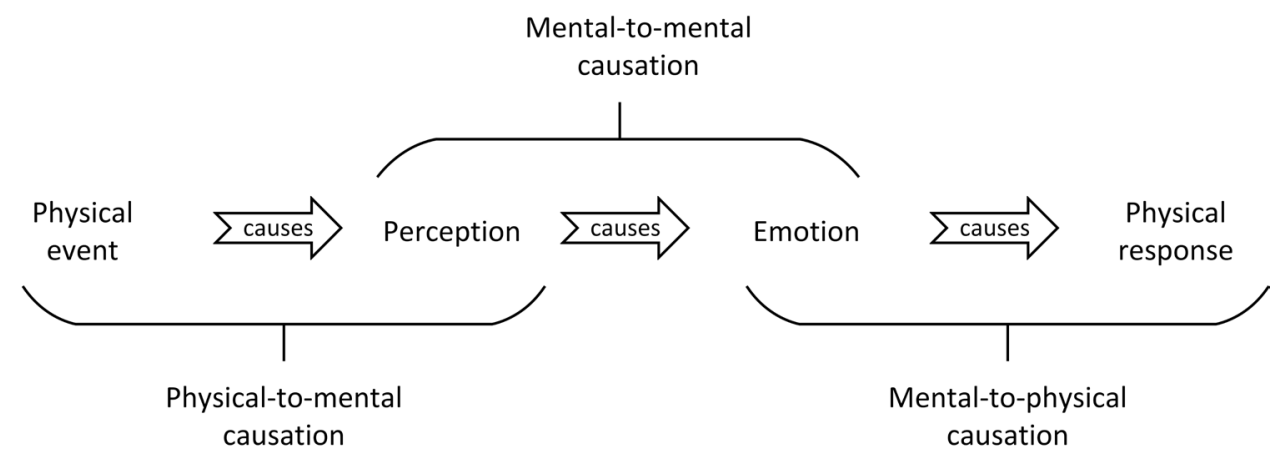

Figure 2.8 The Western folk theory of emotion.

Depending on the abstract concepts inherent in this figure (i.e., perception, emotion and causation), one may formulate three questions of conceptualization:

(1) How is perception conceptualized?

(2) How is emotion conceptualized?

(3) How are causes conceptualized and how does the answer to this question relate to the conceptualizations of perception as cause and emotion as cause?

For each of the three questions above, cognitive linguists have proposed a number of metaphors and metonymies. In what follows, we will discuss them, concept by concept. As with the previous part, the discussion is based on a cross-reading of several authoritative sources in the cognitive linguistic literature. ${ }^{51}$

\subsection{Metaphor and perception}

In addressing the first question, cognitive linguists have proposed two different ways of analysis. The first way considers perception as a target domain in need of metaphorical clarification..$^{52}$ By contrast, the second way considers 
perception as a source domain in its own right for the conceptualization of other target domains. Thereby scholars have particularly emphasized the importance of the domain of perception for the conceptualization of the domains of cognition and time. ${ }^{53}$ This subsection is structured in such a way as to reflect this distinction.

\subsubsection{Perception as a target domain}

How do people conceive and talk about perception? In addressing this question cognitive linguists have emphasized the workings of at least two metaphors and one metonymy, all of which may be diagrammed as in figure 2.9. Let us go through them, one by one.

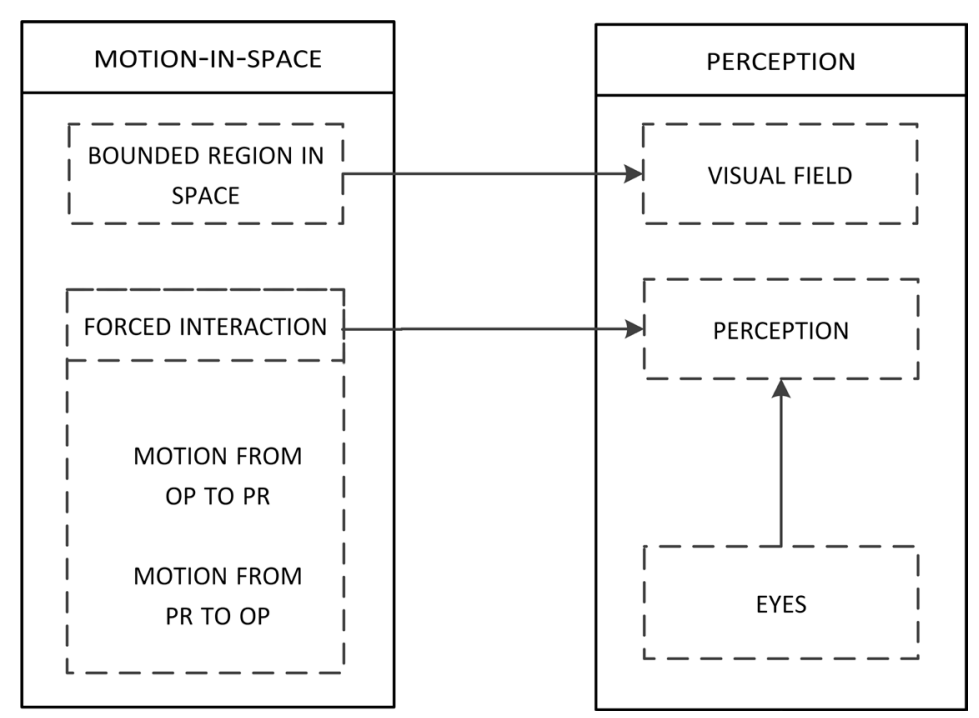

Figure 2.9 Metaphors of perception.

\section{Visual fields are containers}

The first metaphor relates to our concept of a visual field. A visual field refers to all the objects and state of affairs that come into view when you open your eyes in a certain direction. ${ }^{54}$ As the word into in this definition already suggests, our most fundamental understanding of what visual fields are, comes from a metaphor in which a visual field is conceptualized as a bounded region in space or a container. This metaphor, which Lakoff and Johnson call, the VISUAL FIELDS ARE CONTAINERS metaphor, is licensed by such expressions as "The ship is coming into view" or "I have him in sight." Inferential evidence for this metaphor is provided by the systematic relationship between the logic of bounded regions in space and the logic of visual fields (see table 2.3). 
Table 2.3 The inferential correspondences between bounded regions and visual fields.

\begin{tabular}{ll}
\hline Inferences true of bounded regions & Inferences true of visual fields \\
\hline $\begin{array}{l}\text { If you're in a bounded region, you're not out of } \\
\text { that bounded region. }\end{array}$ & $\begin{array}{l}\text { If you're in my visual field, you're not out of } \\
\text { my visual field. }\end{array}$ \\
$\begin{array}{l}\text { If you're out of a bounded region, you're not in } \\
\text { that bounded region. }\end{array}$ & $\begin{array}{l}\text { If you're out of my visual field you're not in } \\
\text { my visual field. }\end{array}$ \\
\hline
\end{tabular}

Perception is a forced interaction between perceiver and object perceived

If a visual field defines that area in space that we see, then, the target domain of perception involves the process of perceiving itself. ${ }^{55}$ Perception may be defined as the process by which the perceiver (abbreviated PR), becomes aware, through his or her perceptual organs, of the objects and states of affairs (abbreviated OP) around him or her. Likewise, when we ask how this process is conceptualized in language, metaphor quickly shows up. The source domain that has been argued to play a fundamental role in this regard is the source domain of spatial interaction. Since interaction is commonly brought about by forced movement (i.e., movement caused by a force), we can further distinguish between two subcases: (1) one metaphor in which the interaction between the PR and the OP takes place through forced movement from the OP to the PR, and (2) an opposite metaphor in which the interaction between the PR and the OP is instantiated by forced movement from the PR to the OP. Following Lakoff, the former type may be described as the PERCEPTION IS RECEPTION metaphor, the latter as the PERCEIVING IS TOUCHING metaphor. ${ }^{56}$

(1) One way to conceive of the first type is by retrieving the VISUAL FIELD AS A CONTAINER metaphor and relating it to the earlier discussed dynamic pattern of ENTRY. This gives rise to an embodied conceptual structure in which the OP, motivated by an internal or external force, enters a bounded region of spatial interaction that coincides with the PR's visual field. This is evidenced in such expressions as "He came into my visual field." In this case the interaction is based on the logic of the containment schema. The OP or trajector (TR) moves from a position outside the PR's visual field or landmark (LM) to occupy a location inside the LM. Spatial interaction or perception, then, takes place as soon as the OP enters the visual field of the PR. Visibility increases with the increase of substance (i.e., the OP) inside the container (e.g., "He is full in view").

The spatial link can also take on a more physical form as when the OP actually makes contact with the PR. Consider, for example, the expression "That view blew me away." Underlying it is the force schema of COMPULSION in which the PR is brought in motion due to the force tendency of the OP, or to use Talmy's distinction between the agonist (Ago) and the antagonist (Ant), as discussed earlier: the PR (Ago) undergoes the effect of the OP (Ant) because the intrinsic force tendency of the OP is stronger than the intrinsic force tendency of the PR. 
(2) By contrast, in the second type, perception occurs "when the perceiver moves his organs of perception to the thing perceived and touches it." ${ }^{57}$ Usually this type of interaction is licensed by the use of such words as on and from ... to as can be illustrated by the following two expressions taken from the screenplay of Eyes Wide Shut:

He puts his hands in his pockets and his eyes wander about the room until they finally rest again on Marion. His eyes wander from voluptuous bodies to slender bodies, from delicate to richly developed figures..$^{58}$

Underlying these expressions is a conceptual metaphor in which the target domain of vision is conceptualized in terms of the source domain of limbs. The word "eyes" thereby designate the "visual limbs" that wander, just as the word "gaze" can designate such visual limbs (e.g., "My gaze is out over the bay"). Following Lakoff, we may summarize the inferential correspondences that go on between both domains as in table $2.4 .^{59}$

Table 2.4 The inferential correspondences between limbs and vision.

\begin{tabular}{ll}
\hline Inferences true of limbs & Inferences true of vision \\
\hline Limbs can be directed. & Vision can be directed. \\
A limb can go in only one direction at a time. & Vision can go in only one direction at a time. \\
Limbs can extend from the body to other objects. & Vision can move from the body to other objects. \\
Tactile perception occurs when a limb touches an object. & Visual perception occurs when the eye-gaze \\
& touches an object. \\
Limbs can pick out objects. & Vision can pick out objects. \\
\hline
\end{tabular}

It is interesting to see how all the perception expressions cited so far focus mainly on the cause of perception (movement $=>$ interaction) rather than on the effect of perception (interaction $=>$ effect). An exception to the rule, as we shall see more clearly in the next section, is the expression "That view blew me away" that focuses more on the emotional effect of the interaction rather than on the coming about of the interaction itself.

Depending on the type of movement (reception versus touching) and the origin of the force that causes the movement, one might distinguish between several metaphorical ways of conceptualizing perception. The origin or source of the force may be located inside the moving entity itself as when an entity moves by using its intention as an internal force. Or the origin of the force may be located outside the moving entity as when the entity is brought in motion by an external force. Combining these elements with the two entities of perception, this leads us to a matrix which might be represented as in table 2.5 . 
Table 2.5 Perception and forced movement.

\begin{tabular}{lll}
\hline Type of movement & $\begin{array}{l}\text { Origin of the force that } \\
\text { causes the movement }\end{array}$ & Linguistic examples \\
\hline $\mathrm{PR}=>$ OP & OP & "My eyes are pulled toward the building." \\
$\mathrm{PR}=>\mathrm{OP}$ & $\mathrm{PR}$ & "My gaze is out over the bay." \\
$\mathrm{OP}=>\mathrm{PR}$ & $\mathrm{OP}$ & "A comet came into my sight." \\
$\mathrm{OP}=>\mathrm{PR}$ & $\mathrm{PR}$ & "She was pulled into his gaze." \\
\hline
\end{tabular}

Eyes for seeing

Lastly, as some of the linguistic examples cited so far already illustrated, there is also a metonymical relationship at work within the conceptual target domain of perception according to which one entity in the schema of perception (i.e., the perceptual organ) is taken as standing for the schema as a whole (i.e., the concept of perception). Consequently, given that seeing and hearing are two of human's core senses, this general mapping further designates two special cases, namely the conceptual metonymy EYES STAND FOR SEEING (e.g., "Keep an eye on him," "Keep your eyes open"), and the conceptual metonymy EARS STAND FOR HEARING (e.g., "I cannot believe my ears," "Walls have ears"). Since both organs are directly related to their function, they also adhere to the more general conceptual metonymy THE INSTRUMENT USED IN AN ACTIVITY STANDS FOR THE ACTIVITY Or THE PERCEPTUAL ORGAN FOR FUNCTION OF THE PERCEPTUAL ORGAN. ${ }^{60}$

\subsubsection{Perception as a source domain}

The metaphorical system just sketched out deals with a conceptual system in which perception is addressed as an abstract target domain. From the opposite side, scholars have also pointed toward a conceptual system in which perception in its own right serves as the source domain for the conceptualization of other abstract target domains such as cognition and time.

\section{Cognition}

It has been argued in the cognitive linguistic literature that metaphor plays an essential role in how people reason about the concept of thinking. Thereby scholars have stressed the importance of a very general metaphor which centres on the idea that the MIND IS A BODY. ${ }^{61}$ This metaphor, in turn, gives rise to a submetaphor according to which the mental faculty of thinking is understood in terms of physical functioning. ${ }^{2}$ One special case of this submetaphor is the metaphor THINKING IS PERCEIVING or UNDERSTANDING IS SEEING. ${ }^{63}$ Considered by many as one of the most common and basic metaphors across the world's languages, this metaphor has a complex set of mappings some of which may be summarized as in figure 2.10. As can be seen in this figure, this metaphor now relocates the conceptual domain of perception from the right side of the table (as target domain) to the left side (as source domain). 


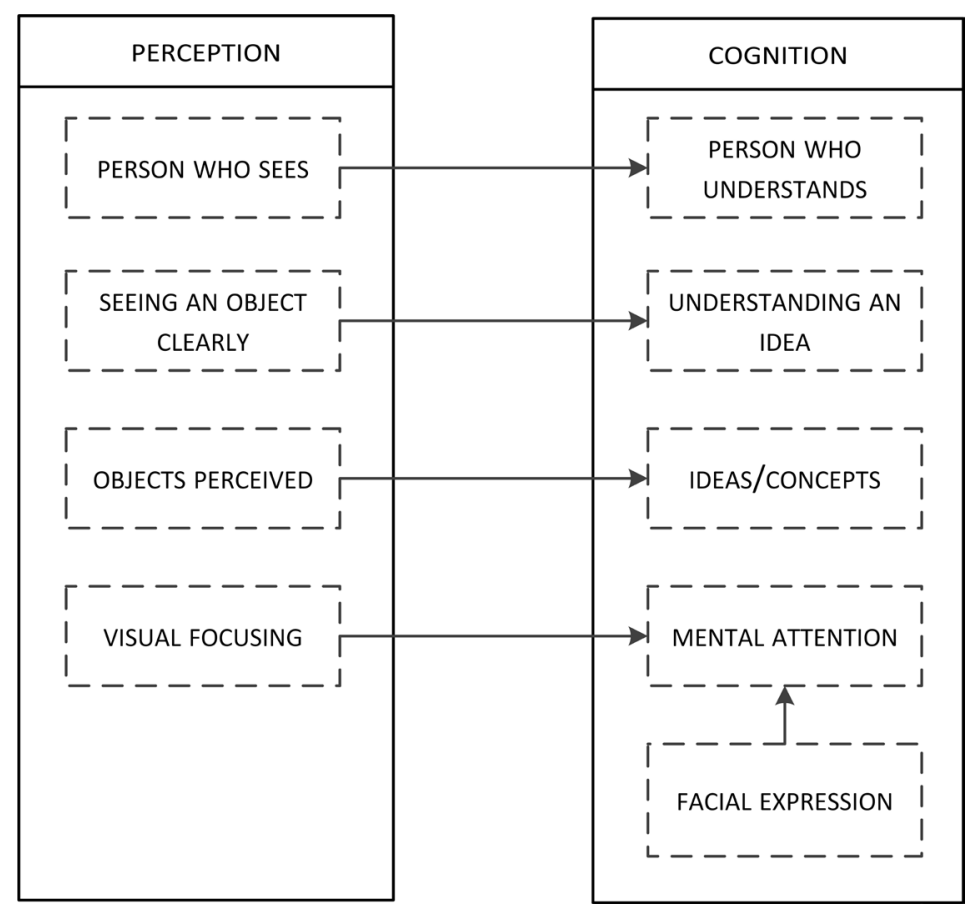

Figure 2.10 Metaphors of cognition.

Hence, when discussing a person's understanding, it follows that someone who apprehends an idea or concept "sees it," whereas someone who is ignorant or incapable of apprehending an idea is "blind" or is "in the dark." Given that perception, as we have seen above, is conceptualized in a metaphorical way, it also follows that the concepts used to conceptualize perception may also be used to conceptualize cognition. This is, for example, how we come to understand thinking similarly in terms of forced movement ("My mind was racing," "I came to that idea"). Likewise, one may identify the existence of a metonymical relationship within the target domain of cognition in which the facial expression of the thinking person is seen as standing for the mental activity of thinking. For instance, several experimental studies demonstrate that facial expressions are not only indicative of emotions, but also of cognitive processes. ${ }^{65}$ Frowning, for example, has been argued to signal hard thinking as when we encounter difficulties in problem-solving. ${ }^{66}$

\section{Time}

Many studies in the field of cognitive linguistics relate the conceptual domain of perception to our conceptualization of time. ${ }^{67}$ In identifying the significant elements within this source domain, scholars have stressed not so much the significance of the activity of perceiving itself, as they have emphasized the essential role of the space around the perceiver. For instance, Lakoff and Johnson have argued that the most basic submetaphor of this general TIME IS SPACE 
metaphor "has an observer at the present who is facing toward the future with the past behind the observer." ${ }^{8}$ They refer to this metaphor as the Time-Orientation metaphor. This metaphor, which may be represented as in figure 2.11, is motivated by such linguistic expressions as "That's all behind us now" or "We're looking ahead to the future." In these mappings the space in front of the perceiver (i.e., the space inside the visual field) is related to the future whereas the space behind the perceiver (i.e., the space outside the visual field) is related to the past.

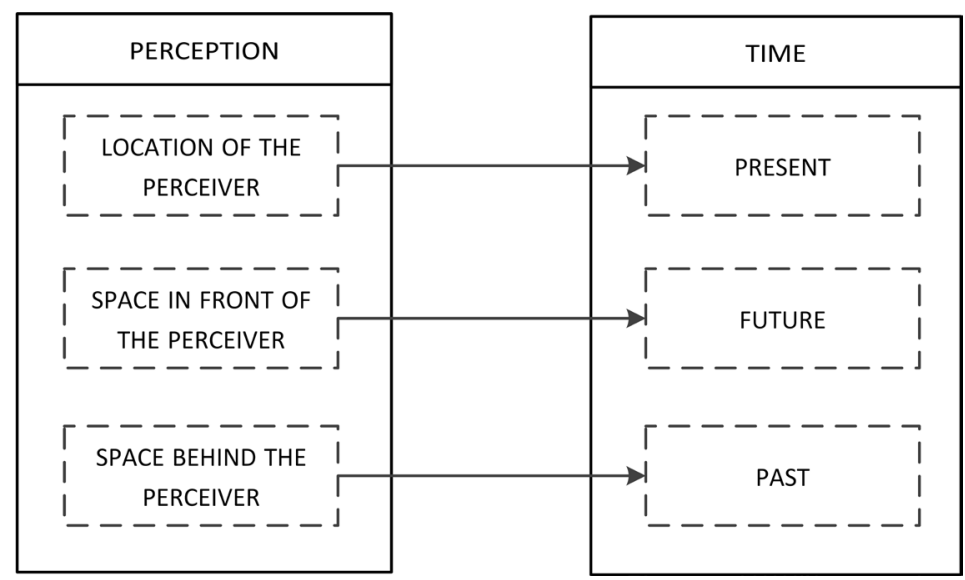

Figure 2.11 The Time-Orientation metaphor.

An exception to this rule, however, was found in the language of Aymara, a Chilean language of the Andes. As research conducted by Núnez and Sweetser revealed, Aymara speakers put the past in front of the observer and the future behind.$^{69}$ As a possible explanation model for this discrepancy both authors refer to the strong emphasis Aymara language put on the KNOwING Is SEEING metaphor. ${ }^{70}$ As we saw above, this metaphor underlies the mapping according to which the object seen by the viewer is mapped onto the idea or concept that constitutes the knowledge. ${ }^{71}$ Consequently, because the past and the future are usually conceived as known and unknown, respectively, it follows, that the past and future are placed in front of and behind the viewer, respectively.

The reason, then, why English speakers still retain a different configuration, despite the fact that they also share the universal KNOWING IS SEEING metaphor, is that both cultures base their temporal conceptions on slightly different aspects of human experiential correlations between time and space. ${ }^{72}$ That is, in contrast to the Aymara speakers, English speakers do not conceive the observer as a static one, but as a moving one. ${ }^{73}$ This implies that what is known has already been seen and remains behind us, while what is unknown has yet to be seen and remains in front of us. As both authors argue, moving persons do not only share the division between "what I can see in front of me" and "what I cannot see behind me" but also the division between "places I haven't yet been to - and thus haven't seen and don't know about" and "places I've been to already - and have thus seen and gained some knowledge about." ${ }^{\prime 4}$ Consequently, the metaphorical pair here is not KNOWN IS IN FRONT and UNKNOWN IS IN THE BACK, but rather KNOWN IS BEHIND and UNKNOWN IS AHEAD. 
It is exactly the notion of motion that let many scholars to distinguish further between two dominant metaphorical models for time in English that usually are integrated with the Time-Orientation metaphor. These are the Moving-Time metaphor and the Moving-Ego metaphor, respectively. ${ }^{75}$ This distinction is basically the same as the duality that we already observed in the metaphorical system of perception. Both models involve movement, "but in one the observer is stationary and time is moving, while in the other the observer is moving and time is stationary." ${ }^{\prime 6}$ Often this distinction is visualized using the image of a time-line. In the first metaphor a time-line is conceived of as a river or conveyor belt on which the perceived object in time is moving toward the perceiver (e.g., "Christmas is coming up"). In the second metaphor the perceiver's point of view moves along the time-line toward the perceived object in time (past or future) (e.g., "We are coming up on Christmas").

\subsection{Metaphor and emotion}

Having discussed the concept of perception and its metaphorical entailments, we can now ask the same question with respect to the concept of emotion. In contrast to perception, emotions have been solely treated as a target domain in need of conceptualization and elaboration. Sketching out some of these metaphors, will be the central aim of the first subsection. In the second subsection, we briefly discuss the conceptualization of a concept that is considered by many to be strongly tied to emotions, namely the concept of relationship (e.g., love, friendship).

\subsubsection{Emotion as target domain}

When considering the question of how people talk about emotions, Zoltan Kövecses' book Metaphor and Emotion stands as a hallmark study in the field of cognitive linguistics. In this book the author illustrates, through detailed cross-linguistic analyses, how many of the concepts we use to reason about emotions reflect widespread metaphorical patterns of thought. As with the metaphors of perception, these emotion metaphors are considered by the author to be deeply rooted in our concrete sensory-motor knowledge. It would be beyond the scope of this book to address all the metaphors identified by Kövecses. We therefore limit ourselves to a discussion of three conceptual relationships, two metaphors and one metonymy, that have been argued to play a crucial role in our conceptualization of emotions. Schematically, they may be represented as in figure 2.12. Likewise, let us consider them each in turn.

\section{Emotions are containers}

We already saw in the previous section how the CONTAINER image schema provided a suitable source domain for conceptualizing a visual field. The same can be said of emotions because one of the most natural ways to talk about emotional states is by making reference to bounded regions in space. Thus, in English it is common to say "I'm in love," "He's in a rage" or "She is in a depression," when one attempts to describe his or her experience of "being in an emotional state." 77 As Kövecses rightly observes, this metaphor coincides with what Lakoff and Johnson more generally coin the STATES ARE LOCATIONS metaphor. ${ }^{78}$ As they point out, this metaphor is fundamental for our understanding of states in that it is difficult not to speak about them without making reference to such features of the CONTAINER schema as an interior and an exterior. This becomes particularly evident in the use of the expressions 
in, out, deep, and so on. As was the case with perception, inferential evidence for this metaphorical mapping can be found in the systematic relationship between the logic of bounded regions in space and the logic of (emotional) states. Following Lakoff and Johnson, this mapping might be summarized as in table 2.6. ${ }^{79}$

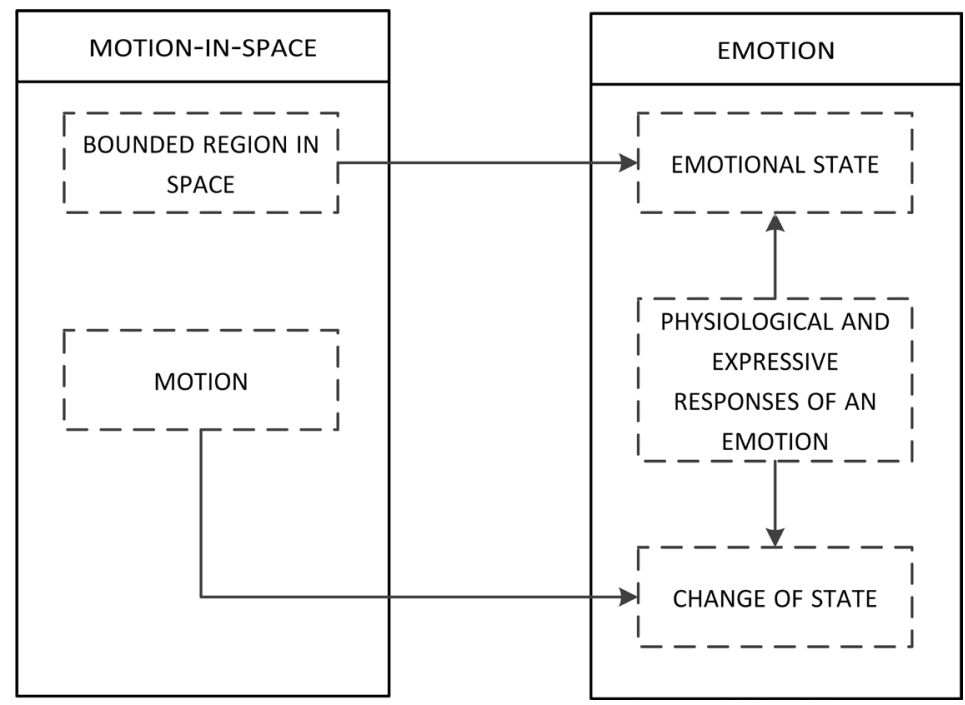

Figure 2.12 Metaphors of emotion.

Table 2.6 The inferential correspondences between bounded regions and (emotional) states.

\begin{tabular}{ll}
\hline Inferences true of bounded regions & Inferences true of states \\
\hline $\begin{array}{l}\text { If you're in a bounded region, you're not out of } \\
\text { that bounded region. }\end{array}$ & If you're in a state, you're not out of that state. \\
$\begin{array}{ll}\text { If you're out of a bounded region, you're not in } \\
\text { that bounded region. }\end{array}$ & $\begin{array}{ll}\text { If you're out of a state you're not in that state. } \\
\text { If you're deep in a bounded region, you are far } \\
\text { from being out of that bounded region. }\end{array}$ \\
$\begin{array}{ll}\text { If you are on the edge of a bounded region, then deep in a state, you are far from being } \\
\text { you're close to being in that bounded region. }\end{array}$ & $\begin{array}{l}\text { If you are on the edge of a state, then you are } \\
\text { close to being in that state. }\end{array}$ \\
\hline
\end{tabular}

Change of state is change of location or motion

The second metaphor conceptualizes a person's change from a nonemotional state to an emotional one as motion from one bounded region in space to another. ${ }^{80}$ Linguistic manifestations of this metaphor can be found in such expressions as "I came out of my depression," "He went crazy" or "She entered a state of euphoria." Similarly, this 
metaphor coincides with what Lakoff and Johnson label more generally the CHANGES ARE MOVEMENTS metaphor or the CHANGE OF STATE IS CHANGE OF LOCATION metaphor. ${ }^{81}$ This metaphor maps each of the inferences true of the logic of movement (i.e., the inferential logic of the SOURCE-PATH-GOAL schema) into the corresponding inferences true of a change-of-state. Following Lakoff and Johnson, this mapping might be summarized as in table 2.7. ${ }^{82}$

Table 2.7 The inferential correspondences between movements and changes (after Lakoff and Johnson).

\begin{tabular}{|c|c|}
\hline Inferences true of movements & Inferences true of changes \\
\hline $\begin{array}{l}\text { If someone moves from Location A to Location B, } \\
\text { it is first in Location A and later in Location B. }\end{array}$ & $\begin{array}{l}\text { If something changes from State A to State B, it } \\
\text { is first in State A and later in State B. }\end{array}$ \\
\hline $\begin{array}{l}\text { If something moves from Location A to Location } \\
\mathrm{B} \text { over a period of time, there is a point at which } \\
\text { it is between Location A and Location B. }\end{array}$ & $\begin{array}{l}\text { If something changes from State A to State B } \\
\text { over a period of time, there is a point at which } \\
\text { it is between State A and State B. }\end{array}$ \\
\hline
\end{tabular}

Physiological and expressive responses of an emotion stand for the emotion

Lastly, as was the case with perception, one may identify a general metonymical association within the target domain of emotions. Kövecses calls this metonymy THE PHYSIOLOGICAL AND EXPRESSIVE RESPONSES OF AN EMOTION STAND FOR THE EMOTION. This metonymy, in turn, adheres to an even more general metonymy, THE EFFECTS OF A STATE FOR THE STATE metonymy. Table 2.8 shows some of the most common source concepts in this metonymy as they were listed by Kövecses. ${ }^{83}$

Table 2.8 Physiological and expressive responses of an emotion for the emotion.

\begin{tabular}{ll}
\hline Source concept & Linguistic example \\
\hline Body heat & "He did it in the heat of passion." \\
Change in heart rate & "He entered the room with his heart in his mouth." \\
Change in respiration & "She was heaving with emotion." \\
Change in the color of the face & "She colored with emotion." \\
\hline
\end{tabular}

As we already have seen in the previous chapter, physiological changes such as the ones listed above have received a great deal of emphasis in several expert theories of emotions. Advocates of these theories conceive of emotion as being primarily constituted by physiological processes and expressive reactions. Seminal research in this regard is Paul Ekman's extensive work on the relationship between facial expressions and emotions. ${ }^{84}$ The author illustrates, through a number of cross-cultural experiments, how various members of different cultures seem to judge the emotions shown in particular facial expressions in an identical way. This led him to categorize facial expressions with six basic emotions: anger, disgust, fear, happiness, sadness and surprise. Happiness, for instance, is typically symbolized by raising of the mouth corners (an obvious smile) and tightening of the eyelids; whereas sadness is symbolized by lowering of the mouth corners, the eyebrows descending to the inner corners and the eyelids 
drooping. More recently, however, this materialist view of emotion as a universal construct has been criticized in the literature. ${ }^{85}$ This discussion, however, is a scientific matter and does not influence the folk theory of emotions according to which people have a natural tendency to refer to facial expressions when talking about emotions.

\subsubsection{Human relationship as target domain}

Let us conclude the section about emotions by uncovering three metaphors that underlie the domain of human relationships. Following Kövecses our focus will be on the interpersonal relationship of friendship. ${ }^{86}$ Although friendship is viewed by many to be an emotion, it is also a rather atypical one. The reason why we tend to associate friendship with emotion is that it appears to involve at least two clear members of the category of emotion, namely, intimacy and affection. As Kövecses' study indicates, people use various metaphors to conceptualize both concepts. In this section, we restrict ourselves to a discussion of three metaphorical ways of conceptualizing the intimacy aspect of friendship. These ways may be summarized as in figure 2.13. As before, let us consider each metaphor in turn.

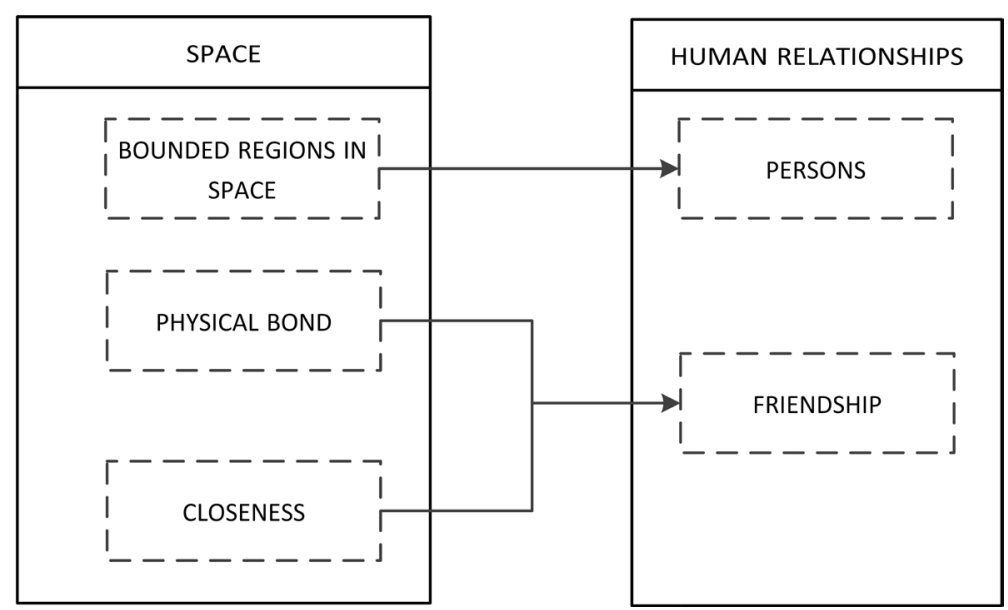

Figure 2.13 Metaphors of human relationships.

\section{Persons are containers}

From the metaphors analysed so far, it should be clear by now that the CONTAINER image schema constitutes one of our most fundamental embodied sources for conceptualizing abstract domains. Friendship forms no exception on this rule as many people share the belief that a friend is someone who we can confide in. Underlying the notion of confiding is the metaphor A PERSON IS A CONTAINER. As Kövecses has pointed out, this metaphor assumes the existence of two selves: a true one which corresponds to a person's "deepest part" where the real person resides, and a superficial one which corresponds to the person's superficial part. This distinction is evidenced in such sentences as the one below (quoted from Kövecses): 
The difference between a best friend and a good friend is a great degree of honesty, complete renunciation of facades and masks which consequently leads to them being themselves in a very natural way-it's not something contrived, or planned, rather it's a very natural state of being. ${ }^{87}$

The form of a mask also connects to another metaphor, LIFE IS A PLAY. To hide your true self in life is to wear a mask, to play a role. The mask serves as the outermost layer of the person that hides the most significant aspects of the self. By contrast, to be your real, true self in life, is to renounce this mask. Friends, then, are containers that do not wear masks, but instead open up to each other so they can experience each other's own true selves and reach a level of intimacy. As we shall demonstrate later in this book, this metaphorical mapping plays a key role in Eyes Wide Shut, where the form of the mask is integrally part of its visual imagery.

\section{Friendship is a physical bond}

Another common way to understand the intimacy of human relationships is through the source domain of physical links or connections. Consider, for example, the following statements about friendship as they were collected by Kövecses during an interview of native speakers of American English (author's emphasis):

True friendship is a bond that can weather the storms of life.... [In] real friendship somehow or other you make the other person feel and they make you feel what connects you is that you have this common, heavy, heavy link in many areas, not that you were just working in the same field or what have you. ${ }^{88}$

Underlying these linguistic expressions is the metaphorical extension of the LINK image schema toward the domain of friendship. As Johnson has argued, the LINK image schema consists of two entities and a physical bond between them. ${ }^{89}$ In the metaphor, then, the two entities are mapped onto the two friends, the physical bond onto the emotional bond and the strength of the bond onto the stability of the relationship. A strong positive emotional relationship is a relationship whose bond is very strong. The opposite is true of a strong negative emotional relationship. Obviously, this metaphor is not limited to friendships alone. As Kövecses stresses, human relationships in general are commonly conceived of as connections, links, ties, bonds, and so on.

\section{Friendship is closeness}

So far we have conceptualized the aspect of intimacy inherent to friendship in two distinctive ways, through the openness of a container and through the strength of a physical bond. A third and last way would be to conceptualize it through the spatial distance between two entities (e.g., two people), in particular, the absence of it, which may be termed closeness. This metaphor, FRIENDSHIP Is CLOSENESS, is grounded in the high-level metaphor AN EMOTIONAL RELATIONSHIP IS A DISTANCE BETWEEN TWO ENTITIES and is motivated by such linguistic examples as "Close friends," "We were tight as a glove," "They were bosom buddies," and "They are as thick as thieves." 


\subsection{Metaphor and causation}

If it comes to explaining how concepts are metaphorical, causation probably serves as one of the best illustrations. In chapter eleven of Philosophy in the Flesh, Lakoff and Johnson have argued that this concept, together with concepts such as events, changes, states, actions, and responses, which are all central to philosophy, are not reflections of a mind-independent reality ${ }^{91}$ Instead they are fundamentally human concepts. We reason about them by making use of metaphors that arise from everyday bodily experience. One such metaphor is what they refer to as the LOCATION EVENT-STRUCTURE metaphor. ${ }^{92}$ This very general metaphor can be conceived of as a single complex mapping with a number of submappings that allow us to understand the main abstract concepts of the target domain of events (e.g., states, change, cause) metaphorically in terms of our more familiar concepts of motion in space (i.e., physical space, force, and motion). We already addressed the first two of them as they were associated with the conceptualization of emotion (i.e., STATES ARE BOUNDED REGIONS and CHANGES ARE MOVEMENTS). The two subsequent submappings of the "state" part of the LOCATION EVENT-STRUCTURE metaphor involve the conceptualizations of CAUSES AS FORCES and CAUSATION AS FORCED MOVEMENT. These metaphors typically come to the surface by the use of verbs that denote forced movement such as bringing, throwing, driving and pulling. They are licensed by such expressions as "He drove her crazy" or "That experience pushed him over the edge." As Lakoff and Johnson point out, in their literal sense, these verbs point to instances of physical movement. ${ }^{93}$ Yet, in these expressions they are used metaphorically in order to designate abstract causation. Following the authors, the inferential logic true of forced movement may be mapped onto the inferential logic true of mental causation, as in table 2.9. ${ }^{94}$

Table 2.9 The inferential correspondences between forced movement and causation.

\begin{tabular}{ll}
\hline Inferences true of forced movement & Inferences true of causation \\
\hline $\begin{array}{l}\text { The application of the force precedes or accompanies } \\
\text { the movement. }\end{array}$ & $\begin{array}{l}\text { The occurrence of the cause precedes or } \\
\text { accompanies the change of state. }\end{array}$ \\
$\begin{array}{l}\text { The movement would not have occurred without the } \\
\text { application of a force. }\end{array}$ & $\begin{array}{l}\text { The change of a mental state would not have } \\
\text { occurred without a cause. }\end{array}$ \\
$\begin{array}{ll}\text { The force impinges on the entity that moves. } & \begin{array}{l}\text { The cause impinges on the entity that } \\
\text { changes state. }\end{array} \\
\end{array}$
\end{tabular}

The question that immediately arises, is of course, how the CAUSES ARE FORCES metaphor applies to the concepts of perception and emotion. Given that the Western folk theory of emotion theorizes both concepts as causes, we might conceptualize them as forces as well: perception as the force that brings about an emotion (the force of perception) and emotion as the force that brings about a behavioral response (the force of emotion) (see figure 2.14). Let us take a closer look at each submapping. As was the case with perception and emotion, we conclude our discussion with a discussion of a metonymy within the target domain of events, namely the EFFECT FOR CAUSE metonymy. 


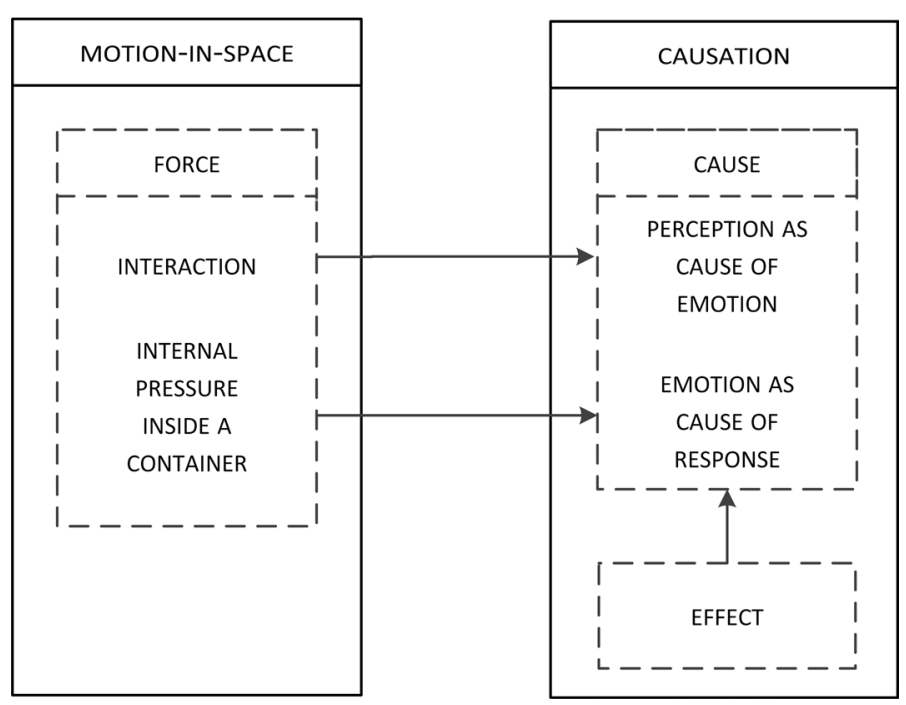

Figure 2.14 Metaphors of causation.

\section{The force of perception}

We already saw above how perception can be conceptualized as a force interaction between a perceiver and an object perceived. Hence, given that perception is the cause of emotion and causes are forces, it follows that the force interaction between the PR and the OP might be viewed as a physical force in its own right that may produce an effect in the perceiver (i.e., the effect of becoming emotional). From the cause of perception (movement $=>$ interaction) we are now shifting away to perception as cause (interaction $=>$ effect). This gives rise to what Kövecses labels the CAUSE OF EMOTION IS A PHYSICAL FORCE metaphor. ${ }^{95}$ In contrast to the interaction metaphor for perception that has to do with the way perception arises, this metaphor primarily emphasizes the way emotions arise. Linguistic examples include such expressions as "He blew me away," "When I found out, it hit me hard" or "That was a terrible blow." Following Kövecses, we might make the underlying metaphorical mappings vivid, as in table 2.10, by means of adopting the basic concepts of Talmy's force dynamic model as discussed earlier. ${ }^{96}$

Table 2.10 The cause of emotion is a physical force.

\begin{tabular}{lll}
\hline Force schema & Source: Physical force & Target: Emotion \\
\hline Agonist & Physical object & The rational self \\
Antagonist & Physical force & The cause of emotion \\
The intrinsic force tendency of the Antagonist & To produce effect in object & $\begin{array}{l}\text { To cause self to become } \\
\text { emotional }\end{array}$ \\
The intrinsic force tendency of the Agonist & To remain unaffected by the force & To remain unemotional \\
\hline
\end{tabular}




\section{The force of emotion}

When it comes to conceptualizing the second part of the folk scenario (emotion as cause of a response), Kövecses has argued that the general-level metaphor EMOTION IS A FORCE might be instantiated by several specific-level metaphors. ${ }^{97}$ One of the best known and most studied metaphors in this regard is what the author labels the EMOTION IS INTERNAL PRESSURE INSIDE A CONTAINER metaphor. In this metaphor people are conceptualized as containers for emotions with the substance inside the container corresponding to the emotion. The substance exerts an internal pressure on the container. When there is very little substance in the container, the pressure is low and thus emotion is at low intensity. In that case, there is little motivation for the self to undertake action (i.e., to respond emotionally). By contrast, with an increase of the substance, the pressure becomes higher, and thus also the intensity of the emotion. The higher the intensity of the internal pressure to bring about an effect, the higher also the intensity of the self's motivation to respond emotionally. If the intensity of internal pressure increases to the point that the substance goes out of the container, an external effect on the container takes place. In that case, the self performs an emotional response. This effect, however, might be prevented insofar as the container is able to keep the substance inside, that is, in case the self succeeds in controlling the emotional response. Likewise, one may lay out these mappings, as in table 2.11, by making use of Talmy's force dynamic model.

Table 2.11 Emotion is a pressure inside a container.

\begin{tabular}{|c|c|c|}
\hline Force schema & Source: Internal pressure & Target: Emotion \\
\hline Agonist & $\begin{array}{l}\text { The container-entity that is affected } \\
\text { by the pressure }\end{array}$ & $\begin{array}{l}\text { The rational self that is affected by the } \\
\text { emotion }\end{array}$ \\
\hline Antagonist & $\begin{array}{l}\text { The substance with pressure inside } \\
\text { the container }\end{array}$ & The emotion (= motivation for action) \\
\hline $\begin{array}{l}\text { The intrinsic force tendency } \\
\text { of the Antagonist }\end{array}$ & Substance-pressure on the container & $\begin{array}{l}\text { The emotion causing the self to } \\
\text { respond }\end{array}$ \\
\hline $\begin{array}{l}\text { The intrinsic force tendency } \\
\text { of the Agonist }\end{array}$ & $\begin{array}{l}\text { The container-entity attempts to } \\
\text { resist the pressure (= attempts to } \\
\text { keep the substance inside) }\end{array}$ & $\begin{array}{l}\text { The rational self attempts not to } \\
\text { respond (= attempts to control the } \\
\text { emotional response) }\end{array}$ \\
\hline
\end{tabular}

Effect for cause

Although Lakoff and Johnson exclude metonymy from their discussion of the LOCATION EVENT-STRUCTURE, other scholars such as Radden and Kövecses make mention of the existence of a general metonymy within the target domain of events, namely the EFFECTS FOR CAUSES metonymy. ${ }^{98}$ In their study both scholars argue that effects, as opposed to causes, serve more often as a metonymical vehicle. They find support for their claim in several subtypes of the EFFECTS FOR CAUSES metonymy. This list includes, among others, the metonymy PHYSICAL/BEHAVIORAL EFFECT FOR EMOTION, as was discussed earlier in the subsection about emotions (e.g., "She was upset"). Since perception and emotion can be conceived of not only as causes, but additionally as effects (i.e., the first as effect of the 
object perceived and the second as the effect of perception), one may conceptualize two additional subtypes of the EFFECTS FOR CAUSES metonymy. Following Radden and Kövecses, they may be referred to as THE PERCEPTION FOR the object PERCeived (e.g., "What a sight") and the emotion for the CAUSE of EMotion (e.g., "She is my joy").

\section{From embodied conceptual structure to film: The challenge of going beyond language}

Having examined how the conceptual structure of mental causation is embodied, we are now in a position to address the relation between embodied conceptual structure and film. As was already mentioned in the introduction, film, as opposed to language, can be seen as a medium that blends various modes of expression, including not only linguistic modes, but also (and above all) non-verbal modes of expression such as pictures and music. As far as cognitive linguistics is concerned, language has always been the centre of attention to provide empirical support for the thesis of embodied cognition. One merely has to consider all the linguistic examples that were cited in this chapter to back the underlying metaphorical and metonymical mappings. Given that this book is about film, however, we are not so much interested in the various ways image-schematic driven metaphors and their interactions with metonymies are licenced by linguistic manifestations, as we are interested in the ways they are manifested at the audio-visual level of films. Motivation for this widening of scope can be found in the nature of conceptual metaphor itself. As we have seen earlier, metaphor and metonymy are considered properties of the mind rather than exclusively properties of language. The latter is merely the surface level in which the embodied conceptual structure is manifested. Given this assertion, it is therefore plausible to assume that language is not the only form of representation which permits the cognitive mechanisms of metaphor and metonymy. Addressing this assumption allows one to avoid an often raised critique against Conceptual Metaphor Theory. This fallacy roughly consists of the claim that cognitive linguists tend to fall in a practice of circular reasoning in which the central proposition (i.e., metaphor is a conceptual phenomenon rather than a linguistic one) is proven by referring back to language. ${ }^{99}$ Indeed, if research on conceptual metaphor is restricted to language, opponents might contend that there is no difference between the conceptual level and the linguistic level, which in turn would significantly jeopardize the theoretical validity of CMT. As Forceville and Jeulink argue:

\footnotetext{
If CMT is correct in emphasizing the centrality of the MIND Is BODY metaphor in human conceptualizing, it should be difficult or even impossible to find non-metaphorical conceptualizations of abstract phenomena... The focus on verbal manifestations of the postulated conceptual metaphors is no help here: detractors might object that the conceptual and the verbal levels are actually the same thing. If this should be the case, CMT claims about the central role of metaphor in cognition would of course be seriously undermined. ${ }^{100}$
}

Going beyond language, however, confronts us with a set of new theoretical challenges that, precisely because of the primacy of language in the literature, has been often overlooked. As has been revealed in the introduction, they involve such questions as to how embodied conceptual structure can be reconciled with the iconic nature of pictures, and how embodied conceptual structure can be bridged to the non-representational nature of musical sounds? The focus of the two subsequent chapters will be on addressing the first question. This task will be divided 
over two chapters. In the first chapter, chapter 3, we will address the question as to how moving pictures can elicit the source tools of embodied meaning-making, in particular, image schemas (as the bodily source of metaphors) and the vehicle concepts of metonymies. In the second chapter, chapter 4, we will illustrate, through various examples, how Kubrick's films make use of these tools in order to convey in visual terms the kind of stories of mental causation as identified in the first chapter.

\section{Conclusion}

In the previous chapter we have identified a conceptual structure that can be seen as representative of the conceptual structure underlying the narratives of Kubrick's films. Following the terminology used in the field of philosophy of mind, we referred to this structure as mental causation. The goal of this chapter, then, was to explore the question as to how mental causation is embodied. In order to do so, we first had to clarify three theoretical concepts that are central to the embodied cognition thesis as put forward by the advocates of cognitive linguistics. These concepts were identified as: image schema, metaphor and metonymy. Having learned about these tools, we were able to show how people use them unconsciously in their everyday linguistic interactions to reason about such concepts as perception, cognition, time, emotion and causation; all of which are central to mental causation. We ended this chapter by raising some of the challenges that arise when one attempts to connect the notion of embodied conceptual structure to the formal level of film. In the next chapter we will consider one of them as we will demonstrate, through an analysis of Kubrick's work, how moving pictures are able to elicit the embodied tools of meaning-making, despite their iconic nature.

\section{Notes}

1. Lakoff and Johnson, "Why Cognitive Linguistics," 249.

2. Due to the abundance of literature on these topics, the task of covering them will be unavoidably schematic and synthetic. For further understanding, we refer the reader to the works quoted in this chapter.

3. Evans and Green, Cognitive Linguistics, 179.

4. Ibid., 179. As Johnson put it, “image schemas are not to be understood either as merely 'mental' or merely 'bodily', but rather as contours of what Dewey called the 'body-mind.” See Johnson, “The Philosophical Significance," 22.

5. Johnson, The Body, 30-31. For a discussion, see also Evans and Green, Cognitive Linguistics, 179; Lakoff, Women, 271.

6. Lakoff and Johnson, Philosophy, 31-32. See also Lakoff, Women, 271.

7. Hampe, From Perception to Meaning; Evans and Green, Cognitive Linguistics, 179-189.

8. Evans and Green, Cognitive Linguistics, 180.

9. Lakoff and Johnson, Philosophy, 34.

10. Ibid., 9-15. See also Johnson, The Meaning of the Body, 139.

11. Johnson, "The Philosophical," 19.

12. Ibid., 20 .

13. Hampe, From Perception to Meaning, 2; Evans and Green, Cognitive Linguistics, 190.

14. Evans and Green, Cognitive Linguistics, 184. 
15. Barsalou, "Perceptual Symbol Systems," 577-609.

16. Evans and Green, Cognitive Linguistics, 180; Johnson, The Body in the Mind, 23.

17. Lakoff and Johnson, for example, use the figure of a circle. See Lakoff and Johnson, Philosophy, 32.

18. Lakoff, Women, 45. For a discussion, see also Correa-Beningfield et al. "Image Schemas vs. Complex Primitives," 348.

19. Johnson, “The Philosophical," 22; Johnson, The Meaning, 139.

20. After Lakoff and Johnson, Philosophy, 32.

21. Johnson, The Meaning, 139.

22. See, among others, Gibbs, Embodiment, 91; Lakoff and Johnson, Philosophy, 32-34.

23. The concept of a trajector (abbreviated TR) derives from Langacker's theory of Cognitive Grammar and relates to the entity in the scene that is typically capable of motion. The entity with respect to which the TR moves, is called the landmark (abbreviated LM). In cognitive linguistic literature it is also common to refer to both entities as the subject and object, respectively. Both terms are also closely related to the principle of Gestalt psychology known as figure-ground segregation. The figure is the entity that is typically privileged in the spatial scene, perhaps due to a definite contour or prominent coloring. It stands out against the ground or reference object which is the entity that is given less prominence in the spatial scene. For a discussion, see Evans and Green, Cognitive Linguistics, 69, 541.

24. After Lakoff and Johnson, Philosophy, 33 .

25. Lakoff and Johnson, Philosophy, 33-34.

26. Johnson, The Body in the Mind, 43.

27. Radden, "Motion Metaphorized," 436.

28. Johnson, The Body in the Mind, 43-44.

29. Radden, "Motion Metaphorized," 437-438.

30. Johnson, The Body in the Mind, 45-47. For a discussion of these schemas, see also Evans and Green, Cognitive Linguistics, 187-189.

31. Talmy, "Force Dynamics," 49-100.

32. Ibid., 53.

33. Dewell, "Dynamic patterns," 369-394.

34. For a good survey and evaluation of this claim, see Gibbs, Embodiment, 90.

35. Lakoff and Johnson, Metaphors We Live By.

36. Evans and Green, Cognitive Linguistics, 190.

37. For a list of common source and target domains, see Kövecses, Metaphor: A Practical Introduction, 17-32.

38. Evans and Green, Cognitive Linguistics, 190.

39. “The Shining: Kubrick's Masterpiece of Suspense, Symbolism, Sets \& Steadicam," accessed October 14, 2018, https://selvedgeyard. com/2017/03/10/the-shining-kubricks-masterpiece-of-suspense-symbolism-sets-steadicam/

40. We will elaborate more on the concept of "narrative absorption" in chapter 5.

41. For a discussion, see, among others, Dirven and Pörings, eds., Metaphor and Metonymy; Lakoff and Johnson, Metaphors We Live By; Kövecses and Radden, "Metonymy"; and Radden and Kövecses, "Towards a Theory of Metonymy."

42. Lakoff and Turner, More Than Cool Reason, 103; Radden and Kövecses, "Towards a Theory of Metonymy," 21.

43. Radden and Kövecses, "Towards a Theory of Metonymy," 21.

44. See ref. no. SK/17/1/11, 119 in the appendix.

45. See also Ruiz de Mendoza Ibánez, "Metaphor, Metonymy," 293.

46. Evans and Green, Cognitive Linguistics, 313-314.

47. Barcelona, Metaphor and Metonymy, 16.

48. Goossens, "Metaptonymy," 323-340; Ruiz de Mendoza Ibánez, "Metaphor, Metonymy"; Velasco, "Metaphor, Metonymy, and ImageSchemas," 47-63.

49. Velasco, "Metaphor, Metonymy, and Image-Schemas," 52. 
50. Ibid., 54 .

51. These sources include, among others, Lakoff, "Reflections," 133-144; Yamanashi, "Metaphorical Modes," 157-175; and Yu, “The Eyes," 663-686 (as far as the concept of perception is concerned); Kövecses, Metaphor and Emotion (as far as the concept of emotion is concerned); and Lakoff and Johnson, Philosophy in the Flesh, Chap. 11 (as far as the concept of causation is concerned).

52. Lakoff and Johnson, Metaphors We Live By, 30; Lakoff, "Reflections," 133-144; Yamanashi, "Metaphorical Modes," 157-175; Yu, “The Eyes," 663-686.

53. For studies that focus on cognition see, among others, Gibbs, Embodiment, 96-99; Johnson, The Meaning of the Body, 165; Lakoff and Johnson, Philosophy in the Flesh, Chap. 12; Yu, "Chinese Metaphors of Thinking," 141-165. For studies that focus on time see, among others, Boroditsky, "Metaphoric Structuring," 1-28; Evans, The Structure of Time; Gentner, "Spatial Metaphors in Temporal Reasoning," 203-222; Gentner, Mutsumi and Boroditsky, "As Time Goes By," 537-565; Lakoff and Johnson, Philosophy in the Flesh, Chap. 10; and Núñez and Sweetser, "With the Future Behind Them," 401-450.

54. Searle refers to this commonsensical definition of a visual field as the "objective visual field." He distinguishes it from what he calls the "subjective visual field," that area of visual consciousness in front of your face that one experiences when closing your eyes. As he states, in the former "everything is seen or can be seen, whereas in the latter "nothing is seen nor can be seen." See Searle, Seeing Things as They Are, 4. This characterization of the visual field, coming from the philosophical tradition of conceptual analysis, differs fundamentally from the conception offered by such neuroscientists as Smythies who defines the visual field more ambiguously as "the spatial array of visual sensations available to observation in introspectionist psychological experiments." See Smythies, "A Note on the Concept of the Visual Field," 369. The difference in definitional criteria thus reflects the intellectual divide that separates the advocates of Direct Realism from the scientific advocates of the representative theory of perception.

55. Like most authors who write about the subject of perception, we will concentrate on vision.

56. Lakoff, "Reflections," 139; see also Yu, “The Eyes," 676.

57. Lakoff, "Reflections," 139.

58. See ref. no. SK/17/1/11 in the appendix.

59. Lakoff, "Reflections," 139.

60. See also Barcelona, Metaphor and Metonymy, 249.

61. Lakoff and Johnson, Philosophy, Chap. 12; Sweetser, From Etymology to Pragmatics.

62. Gibbs, Embodiment, 97.

63. Ibid., 97; Johnson, The Meaning of the Body, 165; Lakoff and Johnson, Philosophy in the Flesh, Chap. 12; Yu, "The Eyes"; Yu, "Chinese Metaphors."

64. Lakoff and Johnson, Philosophy in the Flesh, 239.

65. See, for instance, Scherer, "What Does Facial Expression Express?" 139-165.

66. Kaiser and Wehrle, "Facial Expressions," 287.

67. See, for example, Gentner, "Spatial Metaphors," 203-222; Gentner, Imai and Boroditsky, "As Time Goes By," 537-565; Evans, The Structure of Time; Lakoff and Johnson, Philosophy in the Flesh, Chap. 10.

68. Lakoff and Johnson, Philosophy, 140.

69. Núñez and Sweetser, "With the Future Behind Them," 401-450.

70. Ibid., 438-439.

71. Johnson, The Meaning of the Body, 165.

72. Núñez and Sweetser, "With the Future Behind Them," 438.

73. Ibid., 439.

74. Ibid., 439.

75. Gentner, “Spatial Metaphors," 203-222; Gentner, Imai and Boroditsky, “As Time Goes By," 537-565; Evans, The Structure of Time; Lakoff and Johnson, Philosophy, Chap. 10. 
76. Lakoff and Johnson, Philosophy in the Flesh, 141.

77. Kövecses, Metaphor and Emotion, 52.

78. Ibid., 55; Lakoff and Johnson, Philosophy in the Flesh, 180.

79. Ibid., 181.

80. Kövecses, Metaphor and Emotion, 55.

81. Lakoff and Johnson, Philosophy in the Flesh, 180; see also Radden, "Motion Metaphorized," 425.

82. Ibid., 183.

83. Kövecses, Metaphor and Emotion, 134.

84. See, for instance, Ekman and Friesen, Unmasking the Face; Ekman, Friesen and Ancoli, "Facial Signs," 1125-1134.

85. See, in particular, the criticism voiced by Barrett in How Emotions are Made.

86. Kövecses, Metaphor and Emotion, 87.

87. Ibid., 90.

88. Ibid., 94.

89. Johnson, The Body in the Mind, 117-119.

90. Kövecses, Metaphor and Emotion, 92.

91. As stated in the introduction, Lakoff and Johnson refer to these concepts as "event-structure concepts." See Lakoff and Johnson, Philosophy in the Flesh, 170.

92. Ibid., 179 .

93. Ibid., 194.

94. Ibid., 185.

95. Kövecses, Metaphor and Emotion, 83.

96. Ibid., 84 .

97. Ibid., 65.

98. Radden and Kövecses, "Towards a Theory of Metonymy," 39.

99. See, among others, Forceville, "Non-verbal and Multimodal Metaphor," 19-42; Forceville and Jeulink, "The Flesh and Blood of Embodied Understanding," 37-59; Gibbs and Perlman, “The Contested Impact of Cognitive Linguistic Research," 211-228; Pecher, Boot and Van Dantzig, "Abstract Concepts," 217-248. Another related criticism has to do with the methods of cognitive linguists. It concerns the scepticism that many cognitive scientists (notably psychologists) feel toward the strategy of making conclusions about the conceptual structure on the basis of the individual analyst's own intuitions. To avoid this criticism, it is required that the findings of cognitive linguists are further validated by evidence obtained from convergent operations such as empirical studies. For a more detailed discussion of some of these studies that are supportive of CMT, see Gibbs, Embodiment, 118-121.

100. Forceville and Jeulink, “The Flesh and Blood of Embodied Understanding," 39. 